ARTIGO DE REVIS Ã O

CADERNOS DE

NATUROIOGIA

quanisu

\title{
Uso de terapia floral de Bach em seres humanos: uma revisão integrativa
}

\section{Use of Bach's floral therapy in human beings: an integrating review}

\section{RESUMO}

Introdução: Os Florais de Bach foram criados na década de 1930 por Edward Bach, médico inglês. Trata-se de uma solução hidroalcoólica diluída, com capacidade de reestabelecer o equilíbrio psicofísico do indivíduo. Objetivo: Identificar a produção científica no âmbito da terapia floral, associada aos florais de Bach, já publicados em revistas indexadas, nos idiomas português e espanhol, apresentando as utilizações e os resultados atuais desta terapêutica no Brasil e na América Latina. Materiais e métodos: Revisão integrativa da literatura com base em setenta e quatro estudos publicados em revistas indexadas de alcance internacional. Resultados: Verificou-se que artigos versam sobre a utilização dos florais para a melhora da qualidade de vida, para o tratamento em dermatologia, doenças crônicas não transmissíveis e transtornos mentais. Verificou-se uma predominância do tratamento por via oral e variedades na dosagem e na frequência da administração dos florais. Na maioria dos estudos comparativos o tratamento com a Terapia floral foi considerado francamente superior à outra modalidade de tratamento oferecida, mostrando mais que o dobro de efetividade. Dois estudos ponderaram equilíbrio entre os resultados obtidos nos florais e nas outras formas de tratamento e um estudo apresentou vantagens para o tratamento tradicional, em relação à terapia floral. Nos estudos experimentais, verificou-se uma taxa de melhora superior a 63\%. Conclusão: Os Florais de Bach estão se apresentando como uma modalidade de tratamento eficaz, mesmo quando seu tratamento está focado na doença e não no sujeito. Não foram relatados efeitos adversos, o que sugere esta como uma modalidade tratamento segura, efetiva e inócua.

\section{PALAVRAS-CHAVE}

Essências Florais.

Terapias Complementares.

Humanos.

Qualidade de Vida.

CORRESPONDENTE:

E - M A I L

rjalinemartins@yahoo.com.br

Recebido: $12 / 06 / 2018$

Aprovado: 13/09/2018 


\begin{abstract}
Bach Florals were created in the 1930s by Edward Bach, an English physician. It is a dilute hydroalcoholic solution, prepared from flowers and usually administered orally, in order to reestablish the individual's psychophysical balance. A review of the scientific production in the field of floral therapy, associated with the Bach floral, already published in indexed journals, was carried out in order to map the current uses and results of this therapy in Brazil and in Latin America, based on a Review integrating the literature based on seventy-four studies published in indexed journals of international scope. It has been verified that articles are about the use of floral for the improvement of the quality of life, for the treatment in dermatology, chronic noncommunicable diseases and mental disorders. There was a predominance of oral treatment and varieties in the dosage and frequency of floral administration. In most of the comparative studies the treatment with Floral Therapy was considered to be superior to the other treatment modality offered, showing more than twice the effectiveness. Two studies considered balance between the results obtained in the floral and other forms of treatment and one study presented advantages for the traditional treatment in relation to floral therapy. In the experimental studies, an improvement rate of more than $63 \%$ was observed. It is concluded that Bach flowers are presenting as an effective treatment modality, even when their treatment is focused on the disease and not on the subject. No adverse effects have been reported, which suggests this as a safe, effective and safe treatment modality.
\end{abstract}

Key Words: Flower essences, Complementary Therapies, Human, Quality of Life

\section{INTRODUÇÃO}

Os Florais de Bach foram criados na década de 1930 por Edward Bach, médico inglês ${ }^{1}$. Tratava-se de uma terapia, baseada nas propriedades de cura das plantas e administradas geralmente por via oral, através uma solução hidroalcoólica diluída, que busca o reestabelecer o equilíbrio psicofísico do indivíduo ${ }^{1}$. $\mathrm{Na}$ atualidade existem outros veículos para conservação (glicerina, vinagre), e outros veículos para utilização (gel, creme, balas), embora a solução hidroalcoólica continue sendo a forma mais comum de tratamento.

Atualmente no Brasil, a Terapia de Florais, integra a Política nacional de Práticas Integrativas aprovadas e instituídas no âmbito do SUS no ano de $2018^{2}$. Vale ressaltar que o reconhecimento da terapia floral já existia em alguns estados brasileiros, como o Rio de Janeiro, por exemplo, onde a mesma já era reconhecida como modalidade constitutiva do SUS, no Programa de Terapia Natural, desde o ano de 20093.

Trata-se de uma terapia reconhecida e utilizada em diversos serviços de saúde, no Brasil e no mundo. Entretanto, se tratando de uma prática relativamente nova e de uma profissão ainda sem regula- mentação no Brasil, diversas são as formas e o alcance de tratamento.

Deste modo, o presente artigo tem como objetivo realizar um levantamento da produção científica no âmbito da terapia floral, associada aos florais de Bach, já publicados em revistas indexadas, de modo a mapear as utilizações e os resultados atuais desta terapêutica no Brasil e no mundo.

\section{MÉTODOS}

Para o presente estudo realizamos uma revisão integrativa. Trata-se de uma metodologia capaz de levantar conclusões gerais sobre uma determinada área de estudo. Esta metodologia busca garantir aos profissionais um conhecimento para embasar uma aplicação práticas das evidências que já estão disponibilizadas em estudos científicos publicados, através da produção de uma síntese do conhecimento acumulado ${ }^{4}$.

Os estudos de revisão possuem como vantagem a possibilidade de levantarem diferentes estudos já publicados realizando uma maximização do conhecimento acumulado. A revisão integrativa, constitui modalidade metodológica capaz de agregar estudos com 
metodologias diferentes para definir um melhor enfrentamento de uma questão prática. Isso acontece à medida que se produz um panorama consistente de conceitos, teorias ou questões relevantes para a saúde ${ }^{4}$.

Assim, com base na elaboração de uma pergunta norteadora é possível realizar a compilação de informações bibliográficas e utilizá-las em uma questão prática. Para isso, a revisão integrativa deve ser realizada a partir de seis etapas: A primeira etapa é a definição de uma pergunta norteadora, que definirá os estudos a serem incluídos na revisão integrativa. Em um segundo momento realiza-se uma ampla busca a literatura, a partir de critérios que garantam a confiabilidade da amostra, a partir de critérios claros de inclusão e de exclusão $0^{4}$. Posteriormente, na terceira etapa será feita a extração da totalidade dos dados relevantes dos artigos selecionados, a partir de um instrumento previamente elaborado, garantido a identificação do tipo de estudo, metodologia, tamanho da amostra e método de análise, resultados e implicações. A quarta etapa se realiza uma crítica dos estudos, ponderando suas características e utilidade prática. Na quinta etapa deve se elaborar uma síntese e interpretação dos resultados e, comparam-se os dados levantados. A última etapa consiste na apresentação dos dados, para que o leitor possa analisar criticamente os resultados ${ }^{4}$.

Cientes destas seis etapas, definimos a seguinte questão norteadora: Quais aspectos da vida humana estão sendo tratadas pelos profissionais de saúde com os Florais de Bach, quais as formas de utilização dos florais encontradas na literatura científica de saúde e quais são os resultados alcançados por essa terapêutica?

Com base nestas premissas, o presente estudo realizou um levantamento bibliográfico, no mês janeiro de 2018, a partir dos estudos disponíveis nas bases de dados da Biblioteca Virtual em Saúde (BIREME). Esta base foi selecionada, pelo fato da mesma agregar diferentes bases de dados, nacionais e internacionais e também por sua importância na divulgação de informações científicas em saúde 5 .

Foram considerados como critérios de inclusão para o presente estudo: pesquisas publicadas em qualquer período de tempo, tratassem efetivamente de uma questão de saúde, com o uso dos florais de Bach, que possuíssem o trabalho completo disponível e indexado nas bases de dados.

Portanto, realizamos uma busca avançada com o descritor "Bach" no título e mais um destes descritores também no título "essência" ou "terapia" ou "floral" ou "Florais". Com base nestas associações foram elencados quinhentos e quarenta e oito estudos para compor esta revisão integrativa. Considerando os descritores utilizados, os artigos em língua inglesa foram automaticamente excluídos desta pesquisa. Esta opção metodológica foi feita para delimitar um estudo que contemplasse mais detalhadamente a realidade latino-americana e brasileira.

Foram então excluídos todos os estudos cujo assunto principal não tratasse diretamente o tema das Essências Florais, o que se desdobrou em uma redução para 74 estudos. Foi adicionado então outro critério de exclusão que foi o de não ter texto completo disponível e os estudos foram reduzidos a 37. Excluímos então os textos repetidos, e ficamos com 25 textos. Destes, foram excluídos todos aqueles que não versassem diretamente sobre a utilização dos florais de Bach como terapia para curar, potencializar ou prevenir a saúde em grupos de humanos. $\mathrm{O}$ corpus da pesquisa se reduziu então a 19 trabalhos, oriundos das bases de dados LILACS, CUMED, BDENF-enfermagem. Os trabalhos se encontravam e nos idiomas espanhol e português.

Todos os trabalhos selecionados foram impressos na íntegra para que se realizasse a coleta de dados e foi construído um instrumento de sistematização, composto pelas seguintes categorias: tipo de pesquisa, objeto de estudo, número de participantes, terapêuticas ministradas, tipo de tratamento com florais de Bach, florais utilizados, forma de administrar os florais, período de tratamento e resultados, que para fins de apresentação estarão dispostos em três tabelas diferentes.

A etapa seguinte, ou quarta etapa, compreendeu a análise dos estudos incluídos e foi permeada por uma abordagem organizada para ponderar o rigor e as características de cada estudo. Após a análise detalhada 
de cada estudo procedeu-se a quinta fase que é a discussão e interpretação dos resultados. Nesta fase construímos três categorias decorrentes da reflexão e interpretação dos dados: "Aspectos da vida humana tratados pelos profissionais de saúde com os Florais de Bach", com a identificação das indicações para as quais estão sendo realizados os tratamentos com esta terapêutica, "Formas de utilização da terapia Floral em Seres Humanos", com descrição dos diferentes maneiras de definir e administrar a Terapia Floral e "Resultados obtidos a partir da Terapia Floral", onde se apresentam os resultados e - nos casos em que isso foi possível - realizou-se um comparativo entre a $\mathrm{Te}$ rapia Floral e as outras terapêuticas.

A etapa final do estudo foi concretizada mediante a elaboração do resumo das evidências encontradas na literatura, apresentadas de forma completa $\mathrm{e}$ clara, de modo que leitor tenha fundamentos para ponderar criticamente os resultados apresentados.

Como se trata de um texto sem envolvimento direto de seres humanos, o presente estudo está dispensado de apreciação pelos Comitês de Ética em Pesquisa, conforme a resolução 510/2016 do Conselho Nacional de Saúde ${ }^{6}$.

\section{RESULTADOS}

As pesquisas sobre o tratamento de seres humanos com terapia floral na América Latina são bastante recentes, datando de 2002. Em geral versam sobre a utilização dos florais para a melhora da qualidade de $\operatorname{vida}^{7,8,9,10,11,12,13,14,15,16}$ dermatologia $^{17,18,19,20,21}$, transtornos mentais ${ }^{22}$, doenças crônicas não transmissíveis $^{23,24,25}$.

Os estudos encontrados, são em sua maioria cubanos. A razão para isso pode residir no fato desta terapêutica reconhecida neste país desde 1999, como forma integrante da "Medicina Tradicional e Natural"13,21,23,25. O reconhecimento oficial dentro do país estimula efetivamente suas práticas e pesquisas sobre esta forma de tratamento. Ainda assim, verifica-se a necessidade de um tempo de transição entre o período em que a prática é reconhecida, o movimento de institucionalização das mesmas e as primeiras iniciativas de pesquisa. A maioria dos estu-

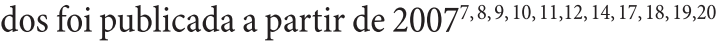
$23,24,25$ o que demostra um espaço de quase uma década para que o trabalho possa ser efetivamente instituído e tratado como objeto de pesquisa.

$\mathrm{O}$ único artigo brasileiro versando sobre o tema ${ }^{7}$ realizava um estudo teórico sobre o tratamento de seres humanos e não apresentava dados empíricos sobre sua utilização. É possível que o recente reconhecimento da Terapia Floral de Bach em nível nacional, como uma prática integrativa ${ }^{2}$, esteja dificultando a institucionalização e a difusão desta terapêutica, bem como a realização de estudos e pesquisas sobre os mesmos.

Identificar as questões e conteúdos da vida humana que estão sendo tratados com florais de Bach, nos ajuda a entender em que sentido estão sendo concebidas as indicações deste tratamento. Vejamos agora um panorama das pesquisas analisadas:

\section{Aspectos da vida humana tratados pelos profissionais de saúde com os Florais de Bach}

De um modo geral, pode-se dizer que existem três grandes vertentes nas quais estão se realizando pesquisas de tratamentos de seres humanos com florais: qualidade de vida, dermatologia e doenças crônicas não transmissíveis.

Os tratamentos na área da qualidade de vida ${ }^{7,8,9}$, 10, 11, 12, 13, 14, 15,16 buscam promover aspectos da saúde, quer melhorando a qualidade do sono ou do raciocínio, reduzindo o estresse, dirimindo medos e retomando a lactância. Estudos desta linha também buscam promover mais equilíbrio e harmonia na vida de pessoas que dada a sua condição de funcionamento mental (quer por atraso, quer por hiperatividade), ou pelo período da vida que estão passando (climatério), medos (como o de dentista), ou hábitos prévios, necessitam curar alguns dos seus sintomas, recuperar seus equilibro e potencializar seu pleno desenvolvimento.

Estas orientações seguem em sintonia com os ideais de Bach, que concebeu este sistema de tratamento para contribuir com o pleno desenvolvimento e com o avanço de cada ser humano, garantindo a eles o pleno usufruto de suas potências. 
Também próximos a esta linha se encontram os tratamentos das doenças crônicas não transmissíveis ${ }^{23,24,25}$, que possibilitam o tratamento de doenças como hipertensão, e a dependência química que se associa à mudança dos padrões de pensamento para a superação de questões que arrastam por longo tempo na vida do sujeito, tabagismo, muitas delas com inegáveis repercussões nos demais membros da família, como é o caso do alcoolismo ${ }^{24}$.

Nas doenças dermatológicas ${ }^{17,18,19,20,21}$ que muitas vezes possuem repercussões na qualidade da interação social destas pessoas, ocorreu, com especial intensidade até o ano de 2010, uma produção intensa de pesquisas sobre a utilização dos florais como recurso terapêutico para essas questões.

Tabela 1- Objeto e participantes dos estudos de Florais de Bach

\begin{tabular}{|c|c|c|c|}
\hline Artigo & Objeto & Participantes e idade & Aspecto tratado \\
\hline $\begin{array}{l}\text { Nosow e Ceolim, } \\
2016\end{array}$ & $\begin{array}{l}\text { Melhoria da qualidade do } \\
\text { sono com florais, }\end{array}$ & Sem participantes & Qualidade de vida \\
\hline $\begin{array}{l}\text { Martell et al, } \\
2016\end{array}$ & $\begin{array}{l}\text { Tratamento de vitiligo com } \\
\text { essências florais }\end{array}$ & 2 participantes 6 e 13 anos & Dermatologia \\
\hline $\begin{array}{l}\text { Matos e Garcés, } \\
2014\end{array}$ & $\begin{array}{l}\text { Tratamento de hipertensão descon- } \\
\text { trolada com terapia floral }\end{array}$ & $\begin{array}{l}60 \text { participantes entre } 21 \text { a } 60 \\
\text { anos }\end{array}$ & $\begin{array}{l}\text { Doenças Crônicas Não } \\
\text { transmissíveis }\end{array}$ \\
\hline Palácio et al, 2013 & $\begin{array}{l}\text { Controle do estresse acadêmico e } \\
\text { cansaço psíquico em estudantes do } \\
\text { primeiro ano universitário }\end{array}$ & $\begin{array}{l}60 \text { participantes não informa a } \\
\text { idade }\end{array}$ & Qualidade de vida \\
\hline Martin, 2012 & $\begin{array}{l}\text { Efeito do floral White chestnut sobre } \\
\text { os pensamentos intrusos }\end{array}$ & $\begin{array}{l}70 \text { participantes entre } 20-60 \\
\text { anos }\end{array}$ & Qualidade de vida \\
\hline $\begin{array}{l}\text { Vegas Rodrigues } \\
\text { e Sanches, } 2012\end{array}$ & $\begin{array}{l}\text { Utilização de florais de bach para } \\
\text { tratamento de alcoolismo crônico }\end{array}$ & $\begin{array}{l}15 \text { participantes entre } 20-50 \\
\text { anos }\end{array}$ & $\begin{array}{l}\text { Doenças Crônicas Não } \\
\text { transmissíveis }\end{array}$ \\
\hline $\begin{array}{l}\text { Barrios, Ramirez } \\
\text { e Román, } 2012\end{array}$ & $\begin{array}{l}\text { Tratamento combinado de florais e } \\
\text { homeopatia para o tratamento de } \\
\text { fumantes }\end{array}$ & $\begin{array}{l}20 \text { participantes entre } 20-69 \\
\text { anos }\end{array}$ & $\begin{array}{l}\text { Doenças Crônicas Não } \\
\text { transmissíveis }\end{array}$ \\
\hline Fernandes, 2011 & Crianças com hiperatividade & 48 participantes entre $0-11$ anos & Qualidade de vida \\
\hline Suárez et al, 2011 & $\begin{array}{l}\text { Tratamento dos sintomas do } \\
\text { climatério com florais }\end{array}$ & $\begin{array}{l}60 \text { participantes entre } 45-59 \\
\text { anos }\end{array}$ & Qualidade de vida \\
\hline Calleja et al, 2010 & $\begin{array}{l}\text { Tratamento da terapia floral na } \\
\text { piodermite complicada }\end{array}$ & $\begin{array}{l}100 \text { participantes entre } 0-15 \\
\text { anos }\end{array}$ & Dermatologia \\
\hline $\begin{array}{l}\text { Diaz, Valdívia e } \\
\text { Lopes, } 2009\end{array}$ & $\begin{array}{l}\text { Uso do floral para tratamento de acne } \\
\text { polimorfo }\end{array}$ & $\begin{array}{l}52 \text { participantes entre } 10-22 \\
\text { anos }\end{array}$ & Dermatologia \\
\hline $\begin{array}{l}\text { Hernandes e } \\
\text { Delgado, } 2009\end{array}$ & $\begin{array}{l}\text { Utilização de florais para dermatites } \\
\text { de causas externas }\end{array}$ & $\begin{array}{l}62 \text { participantes. Não informa a } \\
\text { idade }\end{array}$ & Dermatologia \\
\hline $\begin{array}{l}\text { Marilánes et al, } \\
2007\end{array}$ & $\begin{array}{l}\text { Tratamento do medo de dentista em } \\
\text { crianças }\end{array}$ & 50 participantes entre 6-7 anos & Qualidade de vida \\
\hline Ramos et al, 2007 & $\begin{array}{l}\text { Terapia floral para o hábito de chupar } \\
\text { o dedo }\end{array}$ & 60 participantes entre anos & Qualidade de vida \\
\hline $\begin{array}{l}\text { Guzmán et al, } \\
2007\end{array}$ & Recuperação da lactância materna & $\begin{array}{l}60 \text { (o texto não considera as do } \\
\text { controle como estudo) } 13->37\end{array}$ & Qualidade de vida \\
\hline $\begin{array}{l}\text { Gonzáles, } \\
\text { Delgado, e } \\
\text { Fernandes, } 2005\end{array}$ & $\begin{array}{l}\text { Tratamento de síndrome asteno } \\
\text { depressivo com florais }\end{array}$ & $\begin{array}{l}20 \text { participantes. Não informa a } \\
\text { idade }\end{array}$ & Saúde mental \\
\hline $\begin{array}{l}\text { Calleja, Jimínes e } \\
\text { batista, } 2004\end{array}$ & Tratamento de dermatite externa & 23 participantes entre 1-15 anos & Dermatologia \\
\hline $\begin{array}{l}\text { Reyes et al, } \\
2003\end{array}$ & $\begin{array}{l}\text { Utilização do floral em crianças com } \\
\text { retardo mental }\end{array}$ & $\begin{array}{l}100 \text { participantes entre } 1>12 \\
\text { anos }\end{array}$ & Qualidade de vida \\
\hline Perez et at, 2002 & $\begin{array}{l}\text { Utilização do floral em pacientes } \\
\text { submetidos a cirurgia bucal }\end{array}$ & $\begin{array}{l}33 \text { participantes acima de } 15 \\
\text { anos }\end{array}$ & $\begin{array}{l}\text { Qualidade de vida e } \\
\text { prevenção de danos }\end{array}$ \\
\hline
\end{tabular}

Fonte: autoria própria 


\section{Formas de utilização dos florais encontradas na} literatura científica de saúde

No que tange às formas de utilização dos florais, é possível apontar a existência de três formas de tratamento: a primeira fundamentada nos princípios de Bach, que afirma a necessidade de identificação dos padrões que estão em desarmonia no indivíduo para a prescrição do floral; uma segunda forma de tratamento identificada na literatura, busca promover uma sinergia, agregando todos os florais relacionados com a harmonização da questão a ser tratada. Finalmente foi identificada uma terceira experiência, que inicia o tratamento com um grupo de florais pré-determinado e posteriormente utiliza os florais de forma individualizada, a partir da necessidade do sujeito.

Embora a utilização padronizada de florais em sinergia não esteja em sintonia com o método prescrito por Edward Bach, que dizia que era necessário tratar o doente (e não a doença), e o desaparecimento dos sintomas seriam uma consequência, o método da pré-definição foi o método mais utilizado nos tratamentos com terapia floral7 10, 13, 15, 16, 17, 20,23,25. Duas observações necessitam ser feitas aqui: embora Hernandes, Hernandes e Delgado ${ }^{20}$ descrevam que realizaram um tratamento individualizado junto aos participantes de sua pesquisa, os mesmos só utilizaram 4 essências florais em 62 participantes, o que sugere predefinição do tratamento ou inclusão por características de personalidade, fato que seria necessário para se obter um grupo tão homogêneo em termos de padrões transpessoais. A segunda observação a ser realizada é que Perez et $\mathrm{al}^{16}$, informam que o tratamento era pré-definido, podendo ser individualizado, se fosse necessário.
Como o autor não descreve como ocorreu esta individualização, e como todos eram expostos inicialmente a um tratamento padronizado, optamos por localizar aqui este estudo. Neste grupo foram utilizados em média cinco florais em sinergia, com um estudo relatando o uso de dois florais ${ }^{23}$ e o com maior uso, relatando a utilização de sete florais para tratamento ${ }^{15}$

Já entre os grupos que optaram por um tratamento individualizado ${ }^{11,14,18,19,21,22}$ são descritos em geral dez florais utilizados, porém cada participantes utilizou somente aqueles necessários à sua harmonização.

Dois estudos ${ }^{12,24}$, relataram um esquema diferenciado do usual para o tratamento com terapia floral, com um período inicial do uso do Rescue Remedy, associado a outro flora ${ }^{24}$, ou de forma individualizada ${ }^{12}$.

Quanto ao modo de tratamento, verificou-se que todos fizeram tratamento orais, a maioria com o uso

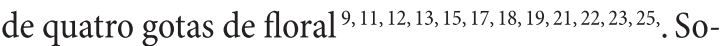
mente uma minoria fez uso de maior quantidade de floral, variando de cinco $^{11}$ a sete gotas ${ }^{16}$.

Quanto à frequência do uso também encontramos variedades de uso, embora a maioria das pesquisas relate uma orientação de seis doses ao dia' ${ }^{9} 12,13,15,16$, $21,22,23$, com uma significativa parte dos estudos referindo o uso dos florais quatro vezes ao $\mathrm{dia}^{10,17,18,19,25}$. A utilização das quatro doses está associada aos estudos mais recentes, porém não se encontrou na literatura nenhuma razão explicativa para este fato.

Também foram relatados estudos com doses de impregnação, por um período de três horas ${ }^{25}$, ou de um dia ${ }^{22}$. Estudos dermatológicos ${ }^{17,18,19,20,21}$ também realizaram tratamentos com cremes ou fomentos onde se adicionava florais para aplicação tópica.

Tabela 2 - Perfil da terapêutica ministrada

\begin{tabular}{lllll}
\hline Artigo & Terapêutica ministrada & Tratamento & Florais utilizados & $\begin{array}{l}\text { Modo de tratamento da } \\
\text { terapia floral }\end{array}$ \\
\hline $\begin{array}{l}\text { Nosow e } \\
\text { Ceolim, 2016 }\end{array}$ & $\begin{array}{l}\text { Reflexão teórica sobre a } \\
\text { indicação dos florais a partir } \\
\text { de uma revisão de artigos da } \\
\text { medline e de livros sobre o } \\
\text { tema }\end{array}$ & $\begin{array}{l}\text { Todos os florais } \\
\text { em sinergia }\end{array}$ & $\begin{array}{l}\text { Sugeridos florais Aspen, } \\
\text { Clematis, Hornbeam Red } \\
\text { Chestnut e White Chestnut }\end{array}$ & $\begin{array}{l}\text { Selecionou florais para tratar } \\
\text { excesso de pensamentos e } \\
\text { para tratar a falta de } \\
\text { ancoramento da mente }\end{array}$ \\
\hline $\begin{array}{l}\text { Martell et al, } \\
2016\end{array}$ & Somente Floral & Todos os florais \\
& & em sinergia & $\begin{array}{l}\text { Crab apple, } \\
\text { Willow, } \\
\text { walnut }\end{array}$ & Oral e tópico 4 gotas, \\
& & & $\begin{array}{l}\text { 4 vezes ao dia, com intervalo } \\
\text { de 2 horas, sublingual + } \\
\text { cremes ou pomadas com } \\
\text { florais aplicados 2 vezes ao dia }\end{array}$ \\
\hline
\end{tabular}




\begin{tabular}{|c|c|c|c|c|}
\hline $\begin{array}{l}\text { Vegas } \\
\text { Rodrigues e } \\
\text { Sanches, } 2012\end{array}$ & Todos tratados com florais & $\begin{array}{l}\text { Oral. Tratamento } \\
\text { inicial pré- } \\
\text { definido e } \\
\text { posteriormente } \\
\text { individualizado }\end{array}$ & $\begin{array}{l}\text { No primeiro mês Cherry } \\
\text { Plum e Rescue remedy. Após } \\
\text { este período avaliação } \\
\text { individualização por padrões } \\
\text { emocionais, com reavaliação } \\
\text { no } 3^{\circ} \text { e } 6^{\circ} \text { mês. } \\
\text { Os outros florais usados } \\
\text { foram: agrimony, cherry } \\
\text { plum, chicory, impatiens, } \\
\text { walnut, mimulous, clematis, } \\
\text { scleranthus, star of betlhem y } \\
\text { Rescue }\end{array}$ & - \\
\hline $\begin{array}{l}\text { Fernandes, } \\
2011\end{array}$ & Somente floral & $\begin{array}{l}\text { Oral. Todos os } \\
\text { florais em } \\
\text { sinergia }\end{array}$ & $\begin{array}{l}\text { Impatiens, vervain e White } \\
\text { chestnut }\end{array}$ & $\begin{array}{l}4 \text { gotas, } 4 \text { vezes ao dia, } 15 \\
\text { minutos de jejum prévio. }\end{array}$ \\
\hline $\begin{array}{l}\text { Suárez et al, } \\
2011\end{array}$ & Somente floral & $\begin{array}{l}\text { Individualizado, } \\
\text { segundo o padrão } \\
\text { transpessoal }\end{array}$ & $\begin{array}{l}\text { Agrimony, cerry plum, } \\
\text { gentiam, Holly, Larch, Olive, } \\
\text { Walnut }\end{array}$ & $\begin{array}{l}\text { Sublingual } \\
5 \text { gotas, } 6 \text { vezes ao dia }\end{array}$ \\
\hline $\begin{array}{l}\text { Calleja et al, } \\
2010\end{array}$ & $\begin{array}{l}\text { Foram divididas em dois } \\
\text { grupos: um tratado só com o } \\
\text { floral e outro com o } \\
\text { medicamento de referência } \\
\text { da dermatologia }\end{array}$ & $\begin{array}{l}\text { Oral e tópico. } \\
\text { Individualizado, } \\
\text { segundo o padrão } \\
\text { transpessoal }\end{array}$ & $\begin{array}{l}\text { Agrimony, beech, walnut, } \\
\text { cherry plum, star of } \\
\text { bethlehem, crab apple, } \\
\text { hornbeam, holly, vine }\end{array}$ & $\begin{array}{l}4 \text { gotas } 4 \text { vezes ao dia } \\
\text { sublingual + aplicação de } \\
\text { creme } 3 \mathrm{x} \text { ao dia em lesões } \\
\text { não úmidas. } \\
\text { Nas lesões úmidas, } 10 \text { gostas } \\
\text { de floral em meio litro de agua, } \\
\text { aplicado com gase a cada } 4 \\
\text { horas, durante } 30 \text { min até } \\
\text { secar e passar para o creme }\end{array}$ \\
\hline
\end{tabular}




\begin{tabular}{|c|c|c|c|c|}
\hline $\begin{array}{l}\text { Marilánes et } \\
\text { al, } 2007\end{array}$ & Somente floral. oral & Pré definido & $\begin{array}{l}\text { Inicialmente com Rescue por } \\
7 \text { dias. Depois se escolheu } \\
\text { aspen ou mímulus, } \\
\text { cominados com agrimony+ } \\
\text { star of betlhem }\end{array}$ & $\begin{array}{l}4 \text { gotas em cima da língua } 6 \\
\text { vezes ao dia. }\end{array}$ \\
\hline $\begin{array}{l}\text { Ramos et al, } \\
2007\end{array}$ & $\begin{array}{l}\text { Divisão em dois grupos de } \\
30 \text {. Um recebeu o tratamento } \\
\text { alopático de referência e o } \\
\text { outro florais de bach. Os dois } \\
\text { grupos também receberam } \\
\text { suporte multidisciplinar }\end{array}$ & Pré definido & $\begin{array}{l}\text { Agrimony, cherry plum, } \\
\text { chicory, impatiens, walnut }\end{array}$ & $\begin{array}{l}4 \text { gotas na boca, } 6 \text { vezes ao } \\
\text { dia, de } 3 \text { em } 3 \text { horas (nos } \\
\text { casos agudos se administrou } \\
\text { mais vezes até a melhora do } \\
\text { processo) }\end{array}$ \\
\hline $\begin{array}{l}\text { Guzmán et al, } \\
2007\end{array}$ & $\begin{array}{l}\text { Divisão em dois grupos de } \\
30 . \text { Um recebeu o tratamento } \\
\text { convencional de referência e } \\
\text { o outro florais de bach. Os } \\
\text { dois grupos também } \\
\text { receberam atividades } \\
\text { educativas sobre aleitamento }\end{array}$ & individualizado & - & $\begin{array}{l}\text { Pacientes com menos de } 30 \\
\text { anos receberam períodos } \\
\text { mais curtos de tratamentos, } \\
\text { já que quando o padrão não } \\
\text { está arraigado notam-se } \\
\text { mudanças em dias ou horas. } \\
\text { Padrões mais arraigados } \\
\text { demandam mais tempo para } \\
\text { melhorias }\end{array}$ \\
\hline $\begin{array}{l}\text { Gonzáles, } \\
\text { Delgado e } \\
\text { Fernandes, } \\
2005\end{array}$ & Só floral & $\begin{array}{l}\text { Tratamento oral } \\
\text { individualizado }\end{array}$ & $\begin{array}{l}\text { Agrimony, } \\
\text { Cherry plum, } \\
\text { Elm, } \\
\text { Gentian, gorse, hornbeam, } \\
\text { mustard, oak, olive, } \\
\text { scleranthus, wild rose }\end{array}$ & $\begin{array}{l}\text { Quatro gotas sublinguais a } \\
\text { cada hora no primeiro dia. } \\
\text { Nos dias restantes, } 4 \text { gotas } 6 \\
\text { vezes ao dia. } \\
\text { Todas as pessoas receberam } \\
\text { elm, olive e scleranthus, mas } \\
\text { de forma individualizada }\end{array}$ \\
\hline $\begin{array}{l}\text { Reyes et al, } \\
, 2003\end{array}$ & $\begin{array}{l}\text { Divididos em } 2 \text { grupos de } 50 \text {. } \\
\text { Grupo experimental } \\
\text { tratamento com florais e } \\
\text { grupo controle sem } \\
\text { tratamento }\end{array}$ & padronizado & $\begin{array}{l}\text { Chesnut bud, clematis, } \\
\text { gentian, elm, White cestnut, } \\
\text { larch }\end{array}$ & $\begin{array}{l}4 \text { gotas sublingual } 6 \text { vezes ao } \\
\text { dia }\end{array}$ \\
\hline $\begin{array}{l}\text { Perez et at, } \\
2002\end{array}$ & $\begin{array}{l}\text { Divididos em dois grupos } \\
\text { um experimental, com } 19 \\
\text { pessoas tratado com florais e } \\
\text { um controle com } 14 \text { pessoas } \\
\text { que recebeu tratamento } \\
\text { convencional }\end{array}$ & $\begin{array}{l}\text { Padronizado, mas } \\
\text { possível de } \\
\text { modificação }\end{array}$ & $\begin{array}{l}\text { Crab appl, elm, mimulus, } \\
\text { White chestnut e rescue }\end{array}$ & $\begin{array}{l}7 \text { gotas sublingual } 6 \text { vezes ao } \\
\text { dia, meia hora antes e depois } \\
\text { não comer, beber, fumar ou } \\
\text { escovar os dentes }\end{array}$ \\
\hline
\end{tabular}

Fonte: autoria própria

\section{Resultados obtidos a partir da terapia floral}

Embora quase todos os estudos possam ser classificados como experimentais, à medida que visam avaliar a efetividade de uma dada intervenção para a recuperação da harmonia e saúde humana, optamos por separar aqueles que também utilizaram um grupo controle, com tratamento convencional ou placebo, à medida que estes podem avaliar uma outra forma de tratar a mesma questão e apresentar um termo de comparação, daqueles que somente apresentam os casos tratados com a terapia floral e apresentam os resultados de forma endógena.

Nos estudos que envolviam comparação ${ }^{8,9,13,14,}$ $15,16,18,19,23$. Dos oito estudos comparativos, em cin$\mathrm{CO}^{8,9,13,14,15,16}$ o tratamento com a Terapia floral foi considerado francamente superior à outra modalidade de tratamento oferecida, mostrando mais que 
o dobro de efetividade. Há que se destacar que todos estes estudos comparativos, estão relacionados à melhora da qualidade de vida, onde a Terapia Floral parece ter o seu melhor desempenho. Dois estudos $^{19,23}$ ponderaram equilíbrio entre os resultados obtidos nos florais e nas outras formas de tratamento, com vantagens e desvantagens para ambos, dependendo do grupo a ser tratado) e um estudo $^{18}$, apresentou vantagens para o tratamento tradicional, em relação à terapia floral.

Já nos estudos experimentais, que somente relataram a intervenção terapêutica em casos tratados com

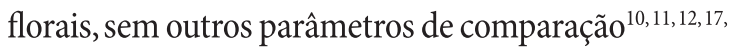
$20,21,22,24,25$ todos apresentavam uma taxa de melhora superior a 63\%. Nenhum estudo relatou qualquer efeito adverso ou piora com a utilização do floral.

Tabela 3 - Perfil do tratamento e resultados obtidos

\begin{tabular}{|c|c|c|c|}
\hline Artigo & Tipo de pesquisa & Período de tratamento & Resultados \\
\hline $\begin{array}{l}\text { Nosow e } \\
\text { Ceolim, } 2016\end{array}$ & $\begin{array}{l}\text { Descritivo, teórico, } \\
\text { reflexivo }\end{array}$ & - & - \\
\hline $\begin{array}{l}\text { Martell et al, } \\
2016\end{array}$ & Relato de caso & $\begin{array}{l}\text { Um mês de tratamento, } \\
\text { com reavaliação mensal } \\
\text { até o sexto mês, de forma } \\
\text { semestral durante um } \\
\text { ano e anualmente até o } \\
\text { quinto ano }\end{array}$ & $\begin{array}{l}\text { Lesões repigmentadas em um mês. Cinco anos } \\
\text { de acompanhamento assintomáticos }\end{array}$ \\
\hline $\begin{array}{l}\text { Matos e } \\
\text { Garcés, } 2014\end{array}$ & $\begin{array}{l}\text { Estudo quase- } \\
\text { experimental. } \\
\text { Comparativo }\end{array}$ & $\begin{array}{l}\text { De uma semana, com } \\
\text { avaliação diária durante } \\
\text { os } 7 \text { dias }\end{array}$ & $\begin{array}{l}\text { Os resultados entre as duas terapêuticas foram } \\
\text { semelhantes com melhor desempenho no quarto } \\
\text { dia. Todos os participantes com hipertensão em } \\
\text { estágio } 1 \text { e } 2 \text { foram controlados nos dois grupos. } \\
\text { A diferença é em relação aos participantes com } \\
\text { hipertensão em estágio 3. Dos três participantes que } \\
\text { haviam em cada grupo, a terapia floral, somente um } \\
\text { conseguiu estabilizar dois. Já no grupo controle, os } 3 \\
\text { hipertensos continuaram sem controle }\end{array}$ \\
\hline $\begin{array}{l}\text { Palácio et al, } \\
2013\end{array}$ & $\begin{array}{l}\text { Ensaio clínico fase } 2 \\
\text { Comparativo }\end{array}$ & - & $\begin{array}{l}\text { Dos estudantes em nível médio de stress } 60 \% \\
\text { melhorou com terapia floral e somente } 20 \% \\
\text { melhorou com placebo. } \\
\text { Dos estudantes de alto nível de estresse } 80 \% \\
\text { melhorou com floral e só } 33 \% \text { melhorou com } \\
\text { placebo }\end{array}$ \\
\hline Martin, 2012 & $\begin{array}{l}\text { Experimental } \\
\text { Duplo cego } \\
\text { Comparativo }\end{array}$ & 14 dias & $\begin{array}{l}\text { White chestnut tem ação efetiva sobre pensa- } \\
\text { mentos indesejados e sua ação difere do placebo. } \\
\text { Resultados significativamente confirmados por } \\
\text { testes estatísticos }\end{array}$ \\
\hline $\begin{array}{l}\text { Vegas } \\
\text { Rodrigues e } \\
\text { Sanches, } 2012\end{array}$ & $\begin{array}{l}\text { Intervenção } \\
\text { terapêutica. } \\
\text { Experimental }\end{array}$ & Seis meses & $\begin{array}{l}\text { Considerou-se satisfatória uma melhora de } 80 \% \\
\text { dos sintomas e ingestão de bebidas. } \\
\text { No primeiro mês } 40 \% \text { melhorou (tratamento } \\
\text { padronizado), no terceiro } 66,6 \% \text { e no sexto mês } \\
93,3 \% \text { haviam melhorados }\end{array}$ \\
\hline $\begin{array}{l}\text { Barrios, } \\
\text { Ramirez e } \\
\text { Román, } 2012\end{array}$ & $\begin{array}{l}\text { Intervenção } \\
\text { terapeutica. } \\
\text { Experimental }\end{array}$ & $\begin{array}{l}\text { Impregnação + } 6 \text { semanas } \\
\text { de tratamento quatro } \\
\text { gotas } 4 \text { vezes ao dia. } \\
\text { colocar } 4 \text { gotas sublin- } \\
\text { gual e manter por um } \\
\text { minuto antes de ingerir. } \\
\text { Revisões foram feitas a } \\
\text { cada } 15 \text { dias }\end{array}$ & $\begin{array}{l}30 \% \text { pararam de fumar e } 70 \% \text { reduziram o } \\
\text { consumo }\end{array}$ \\
\hline $\begin{array}{l}\text { Fernandes, } \\
2011\end{array}$ & $\begin{array}{l}\text { Intervenção } \\
\text { terapeutica. } \\
\text { Experimental }\end{array}$ & 3 meses & $\begin{array}{l}\text { Em } 1 \text { mês, } 50 \% \text { das crianças haviam experimen- } \\
\text { tados melhoras, a maioria ( } 43,8 \%) \text { melhoras } \\
\text { acentuadas. Ao final do terceiro mês } 93,8 \% \\
\text { apresentavam melhoras. Os } 3 \text { que não melhora- } \\
\text { ram foram encaminhados à psiquiatria }\end{array}$ \\
\hline
\end{tabular}




\begin{tabular}{|c|c|c|c|}
\hline Artigo & Tipo de pesquisa & Período de tratamento & Resultados \\
\hline $\begin{array}{l}\text { Suárez et al, } \\
2011\end{array}$ & $\begin{array}{l}\text { Descritivo, longitu- } \\
\text { dinal, prospectivo. } \\
\text { Intervenção } \\
\text { terapêutica. } \\
\text { Experimental. }\end{array}$ & $\begin{array}{l}\text { Seis meses com acompanha- } \\
\text { mento ao final do primeiro, } \\
\text { terceiro e sexto mês. } \\
\text { Nas reavaliações algumas } \\
\text { foram orientadas a } \\
\text { dissolver o remédio na } \\
\text { água (método plus) }\end{array}$ & $\begin{array}{l}\text { Dos } 8 \text { sintomas físicos e } 10 \text { psicológicos } \\
\text { avaliados, houve uma melhora progressiva, em } \\
\text { todos os sintomas mensurados todos os meses, } \\
\text { de modo que ao final do sexto mês de tratamen- } \\
\text { to, surge como pior resultado uma melhora de } \\
63 \% \text { e melhor } 100 \% \text {, }\end{array}$ \\
\hline $\begin{array}{l}\text { Calleja et al, } \\
2010\end{array}$ & $\begin{array}{l}\text { Caso controle. } \\
\text { Comparativo. }\end{array}$ & $\begin{array}{l}10 \text { dias, com avaliação no } \\
3,7 \text { e } 10^{\circ} \text { dias }\end{array}$ & $\begin{array}{l}\text { No tratamento da piodermite primária, em } \\
\text { termos de cura, a terapia tradicional se mostrou } \\
\text { mais adequada. } \\
\text { Entretanto, se somar o conjunto de melhoras e } \\
\text { curas na piodermite primária, o grupo experi- } \\
\text { mental foi mais bem sucedido, com } 91,7 \% \text { dos } \\
\text { casos curados ou melhorados. } \\
\text { No que diz respeito à piodermite secundária, o } \\
\text { tratamento convencional se mostrou mais efetivo }\end{array}$ \\
\hline $\begin{array}{l}\text { Diaz, Valdívia } \\
\text { e Lopes, } 2009\end{array}$ & $\begin{array}{l}\text { Caso controle. } \\
\text { Comparativo }\end{array}$ & 3 meses & $\begin{array}{l}\text { após } 3 \text { meses o tratamento floral se mostrou } \\
\text { superior ao tradicional para os casos de acne } \\
\text { grau I e II, porém na acne grau III o tratamento } \\
\text { convencional obteve maior efetividade }\end{array}$ \\
\hline $\begin{array}{l}\text { Hernandes e } \\
\text { delgado, } 2009\end{array}$ & $\begin{array}{l}\text { Intervenção } \\
\text { terapêutica Experi- } \\
\text { mental, descritivo }\end{array}$ & $\begin{array}{l}10 \text { sessões, com acompa- } \\
\text { nhamento no terceiro, } \\
\text { sétimo e décimo dia }\end{array}$ & $\begin{array}{l}\text { Em } 24 \text { horas , } 82,2 \% \text { dos participantes relatou } \\
\text { melhora. Ao final de dez dias } 95 \% \text { dos partici- } \\
\text { pantes apresentou melhora. E } 4.8 \% \text { apresenta- } \\
\text { vam estado igual }\end{array}$ \\
\hline $\begin{array}{l}\text { Marilánes et } \\
\text { al, } 2007\end{array}$ & $\begin{array}{l}\text { Descritivo, transver- } \\
\text { sal, experimental, } \\
\text { prospectivo. } \\
\text { Intervenção } \\
\text { terapêutica }\end{array}$ & $\begin{array}{l}\text { Um mês com avaliações } \\
\text { aos } 7,14,21 \text { e } 30 \text { dias. }\end{array}$ & $\begin{array}{l}\text { Só com o Rescue, em uma semana, houve } \\
\text { melhora do medo em } 31,7 \% \text { das crianças. } \\
\text { Após um mês de tratamento, } 80 \% \text { das crianças } \\
\text { apresentou melhora }\end{array}$ \\
\hline $\begin{array}{l}\text { Ramos et al, } \\
2007\end{array}$ & $\begin{array}{l}\text { Ensaio clínico } \\
\text { controlado, fase } 3 . \\
\text { Caso controle }\end{array}$ & $\begin{array}{l}\text { O tratamento terminava } \\
\text { com o fim do hábito, com } \\
\text { avaliações aos } 7,15,21 \\
\text { dias, terceiro e sexto mês. }\end{array}$ & $\begin{array}{l}\text { Todos os indicadores em todas as etapas de } \\
\text { avaliação foram favoráveis ao floral. Ao final de } \\
\text { seis meses, no grupo experimental } 66,7 \% \\
\text { estavam curados e } 33,3 \% \text { melhorados, enquanto } \\
\text { no grupo controle } 20 \% \text { curado, } 60 \% \text { melhorado e } \\
20 \% \text { sem mudanças }\end{array}$ \\
\hline $\begin{array}{l}\text { Guzmán et al, } \\
2007\end{array}$ & $\begin{array}{l}\text { Caso controle. } \\
\text { Comparativo }\end{array}$ & - & $\begin{array}{l}86 \% \text { das mulheres tratadas com florais recupera- } \\
\text { ram a lacância, contra } 10 \% \text { do grupo controle }\end{array}$ \\
\hline $\begin{array}{l}\text { Gonzáles, } \\
\text { Delgado e } \\
\text { Fernandes, } \\
2005\end{array}$ & $\begin{array}{l}\text { Estudo experimen- } \\
\text { tal, descritivo, } \\
\text { intervenção } \\
\text { terapêutica }\end{array}$ & $\begin{array}{l}21 \text { dias, com avaliação } \\
\text { semanal }\end{array}$ & $\begin{array}{l}\text { De um total de } 9 \text { sintomas, cinco foram } \\
\text { eliminados, três foram reduzidos em } 80 \% \text { dos } \\
\text { casos o pior indicador obteve } 65 \% \text { de resposta } \\
\text { favorável. Ao final do estudo, } 70 \% \text { referiam } \\
\text { melhoras notáveis, } 19 \text { de } 20 \text { haviam conseguido } \\
\text { diminuir os medicamentos. }\end{array}$ \\
\hline $\begin{array}{l}\text { Calleja, } \\
\text { Jimínes e } \\
\text { batista, } 2004\end{array}$ & $\begin{array}{l}\text { Experimental. } \\
\text { Intervenção } \\
\text { terapêutica }\end{array}$ & $\begin{array}{l}7 \text { dias, com avaliação em } \\
48 \text { horas, } 5 \text { e } 7 \text { dias }\end{array}$ & $\begin{array}{l}\text { Ao final de } 7 \text { dias, } 12 \text { curados, } 4 \text { melhorados e } \\
\text { dois iguais. }\end{array}$ \\
\hline $\begin{array}{l}\text { Reyes et al, } \\
, 2003\end{array}$ & $\begin{array}{l}\text { Experimental, } \\
\text { investigativa, } \\
\text { prospectiva, } \\
\text { transversal, caso } \\
\text { controle, comparativo }\end{array}$ & - & $\begin{array}{l}\text { Ao final do estudo } 60 \% \text { dos alunos do grupo } \\
\text { experimental foram transferidos para escola } \\
\text { regular em contraste com } 30 \% \text { do grupo controle }\end{array}$ \\
\hline $\begin{array}{l}\text { Perez et at, } \\
2002\end{array}$ & $\begin{array}{l}\text { Observacional, } \\
\text { descritivo, transversal, } \\
\text { prospectivo e } \\
\text { experimental. Caso } \\
\text { controle. Comparativo }\end{array}$ & $\begin{array}{l}14 \text { dias. Sete antes e sete } \\
\text { depois da operação, com } \\
\text { acomanhamento } 24 \mathrm{~h}, 72 \\
\text { h e } 7 \text { dias }\end{array}$ & $\begin{array}{l}\text { Todos os resultados pré-operatórios do grupo } \\
\text { experimental foram satisfatórios, contra apenas } \\
29 \% \text { do grupo controle. } \\
\text { No transoperatório todos satisfatórios do experi- } \\
\text { mental contra } 43 \% \text { do controle, no pós operatório } \\
95 \% \text { satisfatório no experimental, e } 86 \% \text { do controle }\end{array}$ \\
\hline
\end{tabular}




\section{DISCUSSÃO}

Os escritos originais de Edward Bach ${ }^{1}$, apontavam a importância de se tratar do indivíduo e não das doenças, de modo que, por sua orientação, não é concebível um tratamento pré-definido para algumas doenças. $\mathrm{O}$ autor considerava que as pessoas reagem de modo diferente às doenças, umas expressando medo, outros com raiva ou falta de esperança, o que demandaria um tratamento individualizado.

Considerando as orientações do percussor deste sistema de cura, todos este tratamentos pré-definidos e baseados na indicação de floral por patologia não deveriam estar sendo ministradas. Bach ${ }^{1}$, valorizava o tratamento a partir das mudanças observadas no estado de espírito rotineiro do indivíduo.

Cabe ainda a observação de que mesmo nos casos em que o tratamento não segue o modo original com que foi concebido, resultados positivos são verificados nas pesquisas e nenhum efeito adverso foi registrado.

Bach também referia que não era necessário se preocupar com dosagem excessiva ou ministrada em curtos intervalos ${ }^{1}$ e também previu uma administração dos florais com intervalos mais curtos nos casos mais urgentes. Mas ele não previa uma dose de impregnação como forma de iniciar o tratamento.

Já as formas de utilização dos florais em compressas, imersões ou banhos, foram previstas nos escritos iniciais do idealizador do sistema ${ }^{1}$.

Quanto às questões de saúde a ser tratadas, nota-se uma grande diversidade de empregos, que incluem desde as doenças crônicas não transmissíveis - maior causa de morbimortalidade brasileira, respondendo por cerca de $70 \%$ das causas de mortes, atingindo fortemente as camadas pobres da população e os grupos mais vulneráveis, como pessoas com baixa renda e escolaridade ${ }^{26}$ - até recuperação da saúde física e potencialização da qualidade de vida, sinalizando uma vasta possibilidade de utilizações deste sistema.

\section{CONCLUSÃO}

Os florais de Bach estão se apresentando como uma modalidade de tratamento para a potencialização da qualidade de vida, cura das doenças do corpo e tratamento das doenças crônicas não transmissíveis. A difusão deste tratamento, na América Latina está associada ao reconhecimento do governo federal, o que possibilita o exercício desta modalidade de tratamento e o desenvolvimento de pesquisas junto a este grupo. As formas de tratamento muitas vezes não estão obedecendo as orientações idealizadas pelo criador do sistema, que refere a necessidade de uma avaliação individualizada do sujeito, mas ainda assim, estão sendo relatadas melhorias e curas na maior parte dos casos. Não foram relatados efeitos adversos, o que sugere esta como uma modalidade tratamento segura, efetiva e inócua.

Os melhores resultados da terapia floral se mostraram associados à melhora da qualidade de vida, em especial nos estudos comparativos. Estudos na área das doenças crônicas não transmissíveis, mostraram-se também bastante efetivos, porém em sua maioria não estavam embasados em pesquisas com comparações de outras terapêuticas para o tratamento da mesma questão.

Os resultados positivos desta terapia necessitam ser aprofundados a partir de pesquisas com metodologias mais rigorosas, uma vez que nem todos os estudos experimentais foram conduzidos a partir de um padrão internacional de pesquisa. Este fato possibilita a existência de vieses de pesquisa, que atualmente procura-se evitar.

Não foi possível fazer uma associação entre o tipo de tratamento (individualizado ou padronizado), com a sua efetividade, o que sugere a necessidade de estudos de efetividade sobre a melhor forma de administrar este tratamento, pois utilizado de forma não convencional, o mesmo também se mostrou efetivo.

Também não foram encontrados parâmetros para justificar a frequência e o uso da dosagem, embora a literatura recente venha fazendo a utilização do método de quatro gotas, quatro vezes por dia.

Verificou-se a necessidade de novos estudos para avaliar também a frequência e a dose necessária à otimização do tratamento e se o sistema de impregnação é realmente efetivo. 


\section{CONFLITOS DE INTERESSE}

Não declarado.

\section{FONTES DE FINANCIAMENTO}

Não declarado.

\section{REFERÊNCIAS}

1. Bach, Edward. Os doze remédios curadores e outros remédios. Mount Vernon. Bach Centre, 1936. Disponível em.: https://www. samsabel.com/os-doze-curadores-e-outros-remedios/ acesso em 23 de maio de 2018 .

2. Brasil. Ministério da Saúde. PORTARIA N ${ }^{\circ} 702$, DE 21 DE MARCO DE 2018. Altera a Portaria de Consolidação no 2/GM/MS, de 28 de setembro de 2017, para incluir novas práticas na Política Nacional de Práticas Integrativas e Complementares - PNPIC. Disponível em: http://bvsms.saude.gov.br/bvs/saudelegis/gm/2018/ prt0702_22_03_2018.html. Acesso em 23 de maio de 2018.

3. Estado do Rio de Janeiro. Lei no 5471, de 10 de junho de 2009. Estabelece no âmbito do estado do rio de janeiro a criação do programa de terapia natural. Disponível em http://alerjln1.alerj. rj.gov.br/contlei.nsf/f25571cac4a61011032564fe0052c89c/46d $9 \mathrm{c} 9 \mathrm{a} 4 \mathrm{cb} 7 \mathrm{bb} 97 \mathrm{a} 832575 \mathrm{~d} 7006624 \mathrm{db}$ ?opendocument. Acesso em 09 de janeiro de 2018

4. Souza MT, Silva MD, Carvalho R. Revisão integrativa: o que é e como fazer. Einstein. 2010;8(1 Pt 1):102-6. Disponível em: http:// www.scielo.br/pdf/eins/v8n1/pt_1679-4508-eins-8-1-0102. Acesso em 09 de janeiro de 2018

5. BIREME; OPAS; OMS. Guia da BVS 2011. São Paulo: BIREME / OPAS / OMS, Março 2011. Disponível em http://bvsmodelo. bvsalud.org/download/bvs/Guia_da_BVS_2011_pt.pdf. Acesso em 09 de janeiro de 2018

6. BRASIL. CONSELHO NACIONAL DE SAÚDE. Resolução 510 de 07 de abril de 2016. Brasília, 2016. Disponível em: http://conselho.saude.gov. br/resolucoes/2016/Reso510.pdf. Acesso em 23 de maio de 2018.

7. COZIN NOSOW, Sheila Katia; CEOLIM, Maria Filomena. Seleção de florais de Bach para melhora da qualidade do sono. Revista de Enfermagem UFPE on line, [S.l.], v. 10, n. 4, p. 3662-3668, ago. 2016 ISSN 1981-8963. Disponível em: <https://periodicos.ufpe.br/ revistas/revistaenfermagem/article/view/11141>. Acesso em 02 fev. 2018. doi:https://doi.org/10.5205/1981-8963v10i4al1141p3662-3668-2016

8. Maceo Palacio Omar, Ramos Guevara Kenia, Maceo Palacio Alberto, Morales Blanco Ileana, Maceo Palacio Maricel. Eficacia de la terapia floral de Bach contra el estrés académico en estudiantes de primer año de estomatología. MEDISAN [Internet]. 2013 Sep [citado 2018 Mayo 25] ; 17( 9 ): 4064-4072. Disponible en: http:// scielo.sld.cu/scielo.php?script=sci_arttext\&pid=\$102930192013000900002\&lng=es.

9. Rodríguez Martín Boris C. Esencias florales de Bach: efecto del White Chestnut sobre los pensamientos intrusos indeseados. Rev Cubana Invest Bioméd [Internet]. 2012 Jun [citado 2018 Feb 02] ; 31 ( 2 ): . Disponible en: http://scielo.sld.cu/scielo.php?script=sci_ arttext\&pid=S0864-03002012000200010\&lng=es.

10. Callís Fernández Sureima. Terapia floral de Bach en niños con manifestaciones de hiperactividad. MEDISAN [Internet]. 2011 Dic [citado 2018 Mayo 25] ; 15( 12 ): 1729-1735. Disponible en: http:// scielo.sld.cu/scielo.php?script=sci_arttext\&pid=S1029$30192011001200007 \& \operatorname{lng}=\mathrm{es}$.

11. López Suárez, Julio Cesar; el Toro Mosquera, Giset de los Angeles; Padrón Cordero, Lien; Corrales Zamora, Yulaimi;Fernández de Posada, Yuliem. La Terapia Floral de Bach en el tratamiento del síndrome climatérico femenino / Bach flower therapy in the treatment of female climacteric syndrome Disponível em: http://bvs.sld.cu/revistas/mciego/ vol17_supl1_\%202011/articulos/t-12.html
12. GARCIA MILANES, Marylena et al . Comportamiento clínico del miedo infantil al estomatólogo con tratamiento de flores de Bach. Rev Cubana Estomatol, Ciudad de La Habana, v. 44, n. 3, sept. 2007 Disponible en $<$ http://scielo.sld.cu/scielo.php?script=sci_ arttext\&pid=S0034-75072007000300010\&lng=es\&nrm=iso $>$. accedido en 02 feb. 2018.

13. MARTINEZ RAMOS, Mayra Raquel et al . Eficacia de la terapia floral de Bach aplicada en niños de primer grado con hábito de succión digital. Rev Cubana Estomatol, Ciudad de La Habana, v. 44, n. 3, sept. 2007 . Disponible en <http://scielo.sld.cu/scielo. php? script=sci_arttext\&pid=S0034-75072007000300004\&lng=es\& nrm=iso $>$. accedido en 02 feb. 2018

14. Galano Guzmán DG, González Gómez D, Nordet Torres D, Carrión Stuart L, Nicó García D, Ortiz Barral D, Cleger Fonseca D, et al. Eficacia de la terapia floral de Bach en la recuperación de la lactancia materna exclusiva. Revista de Información Científica [Internet]. 2007 [citado 2018 Feb 2];54(2):[aprox. 0 p.]. Disponible en: http://www. revinfcientifica.sld.cu/index.php/ric/article/view/1404

15. Francia Reyes María Elena, Sandoval López Onelia, Hernández Martínez Yolanda, Suárez Llano Orquídea, Arias Hernández Irma. Aplicación de la terapia floral de Bach en niños con retardo del desarrollo psíquico. Rev Cubana Med Gen Integr [Internet]. 2003 Ago [citado 2018 Mayo 25] ; 19( 4 ): . Disponible en: http://scielo. sld.cu/scielo.php?script $=$ sci_arttext\&pid $=$ S086421252003000400005\&lng=es.

16. Perojo Pérez P, Rodríguez Chávez M, Delgado Buela R, Lorenzo Montesinos Á, de la Torres Díaz N, González González I. La terapia floral de Bach en pacientes de cirugía bucal. Medimay [revista en Internet]. [citado $2018 \mathrm{Feb} 2$ ];9(1):[aprox. 8 p.]. Disponible en: http:// revcmhabana.sld.cu/index.php/rcmh/article/view/110

17. Fernández Martell Regla María, Sánchez Fernández Clara Milagros, Martín Suárez María de los Ángeles, Hernández González Samuel Isaac, Dopico Toledo Acela, Véliz Guerra Leidi Tamara. Tratamiento del vitiligo con esencias florales de Bach. Presentación de casos. Rev.Med.Electrón. [Internet]. 2016 Feb [citado 2018 Feb 02] ; 38( 1 ): 105-111. Disponible en: http://scielo.sld.cu/scielo. php? script=sci_arttext $\&$ pid $=$ S1684-18242016000100011\&lng=es.

18. Pérez Calleja, Norma; Sotolongo Díaz, Dunia; Alejo Batista, Yamilet; Martín Pérez, Agustín; Matos Rosario, Auderys;Pollo Inda, Jorge D. Utilidad de la Terapia Floral de Bach en las piodermitis no complicadas Mediciego; 16(supl. 1)jun. 2010. Graf. Disponível em: http://bvs.sld.cu/revistas/mciego/vol16_ supl1_10/articulos/t-12.html

19. Sotolongo Díaz, Dunia; Obregón Valdivia, Pedro Pablo; González López, Magalys. Utilización de la terapia floral de Bach en el acné polimorfo / Use of Bach floral therapy in the polymorphous acne. http://bvs.sld.cu/revistas/mciego/ vol15_02_09/articulos/a4_v15_02_09.html

20. Sánchez Hernández, Vivian de la C; Sánchez Hernández, Tania; Perdomo Delgado, Johann. Utilización de la terapia floral de Bach según patrón transpersonal en las dermatitis de causa externa. Rev. medica electron; 31(3)mayo-jun. 2009. tab http:// www.revmatanzas.sld.cu/revista\%20medica/ano\%202009/ vol3\%202009/tema03.htm

21. Pérez Calleja, Norma; Pérez Jiménez, Yolanda; Alejo Batista Yamilet. Utilizacion de la terapia floral de Bach en la dermatitis externa. http://bvs.sld.cu/revistas/mciego/vol10_supl2_04/ articulos/a3_v10_supl204.htm 
22. González Pla, Evelyn Anie; Perdomo Delgado, Johann; Fernández Fernández, Aracelys. TRATAMIENTO DEL SÍNDROME ASTENO-DEPRESIVO CON TERAPIA FLORAL

BACH. societat per a l'estudi i la difusió de la terapia del dr bach de catalunya http://docplayer.es/23444050-Tratamiento-delsindrome-asteno-depresivo-con-terapia-floral-bach.html

23. Alvarez Matos Dunia, Matos Garcés Maikel. Efectividad de la terapia floral en pacientes con hipertensión arterial descontrolada. MEDISAN [Internet]. 2014 Ago [citado 2018 Mayo 25] ; 18( 8 ):

1081-1087. Disponible en: http://scielo.sld.cu/scielo. php? script $=$ sci_arttext\&pid $=$ S1029 $30192014000800007 \& \ln g=$ es

24. CONTRERA VEGA, Noraima; CEDENO RODRIGUEZ, Enriqueta; VAZQUEZ SANCHEZ, Monserrat. Efectividad de la terapia floral de Bach en pacientes con alcoholismo crónico. MEDISAN, Santiago de Cuba, v. 16, n. 4, p. 519-525, abr. 2012 . Disponible en <http:// scielo.sld.cu/scielo.php?script=sci_arttext\&pid=S1029$30192012000400005 \& \ln =\mathrm{es} \& \mathrm{nrm}=\mathrm{iso}>$. accedido en 02 feb. 2018.
25. Mondéjar Barrios, María Dolores; Zamora Ramírez, Tania Pérez Román, Eduardo. Tratamiento con terapia floral de Bach y homeopatía a fumadores del Policlínico Norte de Morón.Mediciego; 18(supl.1)jun. 2012. Tab. Disponívem em: http://bvs.sld.cu/ revistas/mciego/vol18_supl1_2012/articulos/t-7.html

26. Duncan Bruce Bartholow, Chor Dóra, Aquino Estela M L, Bensenor Isabela M, Mill José Geraldo, Schmidt Maria Inês et al . Doenças crônicas não transmissíveis no Brasil: prioridade para enfrentamento e investigação. Rev. Saúde Pública [Internet]. 2012 Dec [cited 2018 May 23] ; 46 (Suppl 1): 126-134. Available from: http://www.scielo.br/scielo.php?script=sci_arttext\&pid=S0034$89102012000700017 \& \operatorname{lng}=$ en. http://dx.doi.org/10.1590/ S0034-89102012000700017. 